\title{
Targeting the HGF/Met Signaling Pathway in Cancer
}

\author{
Fabiola Cecchi ${ }^{1}$, Daniel C. Rabe, and Donald P. Bottaro \\ Urologic Oncology Branch, Center for Cancer Research, National Cancer Institute, National \\ Institutes of Health, Bethesda, MD 20892
}

\begin{abstract}
Under normal conditions, hepatocyte growth factor (HGF)-induced Met tyrosine kinase (TK) activation is tightly regulated by paracrine ligand delivery, ligand activation at the target cell surface, and ligand activated receptor internalization and degradation. Despite these controls, HGF/Met signaling contributes to oncogenesis and tumor progression in several cancers and promotes aggressive cellular invasiveness that is strongly linked to tumor metastasis. The prevalence of HGF/Met pathway activation in human malignancies has driven rapid growth in cancer drug development programs. Pathway inhibitors can be divided broadly into biologicals and low molecular weight synthetic TK inhibitors; of these, the latter now outnumber all other inhibitor types. We review here the basic properties of HGF/Met pathway antagonists now in preclinical and clinical development as well as the latest clinical trial results. The main challenges facing the effective use of HGF/Met-targeted antagonists for cancer treatment include optimal patient selection, diagnostic and pharmacodynamic biomarker development, and the identification and testing of optimal therapy combinations. The wealth of basic information, analytical reagents and model systems available concerning HGF/Met oncogenic signaling will continue to be invaluable in meeting these challenges and moving expeditiously toward more effective disease control.
\end{abstract}

\section{Keywords}

Hepatocyte growth factor; Met; cancer drug development

\section{Introduction}

The $M E T$ oncogene was first isolated from a human osteosarcoma-derived cell line on the basis of its transforming activity in vitro, caused by a DNA rearrangement where sequences from the $T P R$ (translocated promoter region) locus on chromosome 1 were fused to MET sequence on chromosome 7 (TPR-MET) (1). A similar gene rearrangement was later found in patients with gastric carcinoma $(2,3)$. Isolation of the full-length $M E T$ proto-oncogene sequence revealed that it encoded a receptor tyrosine kinase (TK) (2). The subsequent identification of hepatocyte growth factor (HGF) as the natural ligand for the Met receptor protein (4), and the identity of scatter factor (SF) and HGF united a collection of findings demonstrating that a single receptor transduced multiple biological activities including motility, proliferation, survival and morphogenesis (5-8).

Both HGF and Met proteins are processed proteolytically from single chain precursors into mature disulfide linked heterodimers. Both are widely expressed early in development and deletion of either gene lethally disrupts embryogenesis $(5,6,8)$. The widespread expression

\footnotetext{
${ }^{1}$ Correspondence: Urologic Oncology Branch, Center for Cancer Research, National Cancer Institute, Bldg 10 CRC Rm 1W-5832, 10 Center Drive MSC 1107, Bethesda, MD 20892-1107 USA, Telephone (301) 402-6499, Fax (301) 402-0922, cecchif@ mail.nih.gov.
} 
of both $M E T$ and $H G F$ genes persists throughout adulthood and upregulation of $H G F$ expression after kidney, liver or heart injury suggests that pathway activation protects against tissue damage and promotes tissue repair and regeneration (9-13). The strong interaction between HGF protein and cell surface heparan sulfate (HS) proteoglycans is broadly relevant to HGF biology and HS can be thought of as an HGF co-receptor, modulating HGF binding, Met activation and cellular responses (14-19). Similar to fibroblast growth factor (FGF) signaling, which requires not only FGF-HS binding, but also FGF receptor-HS interaction (20), evidence suggests that HS may facilitate HGF signaling through interactions with both HGF and Met (21). Upon HGF binding, Met autophosphorylation occurs on tyrosine residues Y1234 and Y1235 (numbered according to GenBank J02958) within the activation loop of the TK domain, inducing kinase activity, while phosphorylation on Y1349 and Y1356 near the carboxyl terminus forms a docking site for intracellular adapters that transmit signals downstream $(6,8)$. An intact docking site is required for transformation and metastasis (8). Critical signaling mediators in this pathway include Grb2, Gab1, phosphatidylinositol 3-kinase (PI3K), phospholipase C-gamma (PLC $\gamma)$, Shc, Src, Shp2, Ship1 and STAT3 $(6,8)$.

\section{Oncogenic HGF/Met Signaling}

Under normal conditions, hepatocyte growth factor (HGF)-induced Met tyrosine kinase (TK) activation is tightly regulated by paracrine ligand delivery, ligand activation at the target cell surface, and ligand activated receptor internalization and degradation. Despite multiple controls, pathway deregulation occurs in a variety of neoplasms. Among the hundreds of genes upregulated by HGF are those encoding proteases required for HGF and Met processing, as well as $M E T$, creating the potential for its overexpression through persistent ligand stimulation (6). Indeed, $M E T$ overexpression is characteristic of several epithelial and mesenchymal cancers and is an independent prognostic factor associated with adverse outcome (22). MET gene amplification is thought to be an important driver of metastasis in a subset of lung cancers that acquire resistance to agents targeting epidermal growth factor family members (23). Other mechanisms of oncogenic pathway activation include aberrant paracrine or autocrine ligand production, constitutive kinase activation in the presence or absence of $M E T$ gene amplification, and $\operatorname{MET}$ gene mutation $(5,24,25)$. Missense MET mutations occur in several cancers; the earliest reported mutations were found exclusively in the Met TK domain and were associated with hereditary and sporadic forms of papillary renal cell carcinoma (PRC) $(26,27)$. Mutations throughout the $M E T$ coding sequence were later found in lung cancer and in head and neck cancers $(28,29)$.

The impact of specific MET mutations have been studied act at the molecular, cellular and organismal levels. Structural modeling of the Met TK domain indicated that activating PRC mutations interfere with an intrinsic mode of autoinhibition $(30,31)$. Early cell-based investigations confirmed that kinase activity was deregulated in various mutant forms and revealed that these could have distinct biological effects. For example, the PRC-associated mutations D1228H/N and M1250T showed enhanced kinase activity, Ras pathway activation and focus formation, while L1195V and Y1230C more effectively activated PI3K, promoting cell survival, soft agar colony formation and matrix invasion $(32,33)$. Although mutations that were reconstituted in HGF-producing cells (such as NIH3T3) could not rigorously address the role of ligand binding in oncogenesis, later studies showed that mutations expressed in epithelial cells required added ligand for soft agar colony formation and that colony formation by NIH3T3 bearing Met M1250T could be blocked by ligand binding antagonists (34). PRC-associated MET mutations also have been investigated in mice by engineering changes in the murine $M E T$ locus (35). Interestingly, mice harboring D1226N, Y1228C, and both M1248T and L1193V mutations developed sarcomas with high frequency and some lymphomas, whereas the M1248T mice developed carcinomas and 
lymphomas; no mice developed PRC (35). Furthermore, analogous to the trisomy of chromosome 7 frequently observed in human PRC tumors, trisomy of chromosome 6 (containing the murine MET locus) and preferential duplication of the mutant MET allele was observed in most tumors. These results independently confirm the oncogenicity of PRCassociated MET mutations in vivo and suggest that distinct mutations influence the types of cancers that develop in mice (35).

Other alterations in the $M E T$ coding sequence have been identified in regions encoding the extracellular semaphorin domain (E168D, L229F, S323G, and N375S) and the intracellular juxtamembrane (JM) domain (R988C, T1010I, S1058P, and exon 14 deletions) of non-small cell lung carcinoma (NSCLC)-derived cell lines, in $12.5 \%$ of small lung cell cancer (SCLC) cases, as well as in $8 \%$ of samples of lung adenocarcinoma tissues $(29,36-38)$. Some of these mutations activate proliferation, motility and invasiveness in cultured cells (29). Importantly, the JM domain regulates ligand-dependent Met internalization: Y1003 is phosphorylated in response to HGF binding and recruits $\mathrm{c}-\mathrm{Cbl}$, leading to Met ubiquitination and degradation (1). In Met JM domain mutants missing exon 14, the loss of Y1003 results in Met accumulation at the cell surface and persistent HGF-stimulated signaling that leads, in turn, to increased transforming activity and tumorigenic potential (1). Overall, $M E T$ mutation occurs at a lower frequency than most other mechanisms of pathway activation in tumors; nonetheless, mutations provide strong direct evidence of the pathway's oncogenic potential and may identify patients most likely to benefit from Met-targeted therapeutics.

Consistent with the role of this pathway in organogenesis, oncogenic Met signaling resembles developmental transitions between epithelial and mesenchymal cell types normally regulated by HGF: increased protease production coupled with cell dissociation and motility promotes cellular invasion through extracellular matrices, enabling tumor invasiveness and metastasis. Conversely, silencing the endogenous, overexpressed $M E T$ gene in tumor cells suppresses tumor growth and metastasis, and induces the regression of established metastases in mouse models (39). In addition, HGF/Met signaling in vascular endothelial cells stimulates tumor angiogenesis, facilitating tumor growth for cancers that are growth-limited by hypoxia, and independently promoting tumor metastasis. Hypoxia alone upregulates MET expression and enhances HGF signaling in cultured cells and mouse tumor models (40).

\section{The Development of Cancer Drugs Targeting the HGF/Met Pathway}

The prevalence of HGF/Met pathway activation in human malignancies has driven rapid growth in drug development programs. Agents currently under development as HGF/Met pathway inhibitors can be broadly subdivided into biologicals and low molecular weight synthetic compounds (Figure 1). Biologicals, or protein-based agents, act through a variety of mechanisms and possess target selectivity and pharmacokinetic (PK) properties that are predictable and often desirable. Nonetheless, their size typically restricts their action to extracellular events and their complexity impacts drug manufacture, routes of administration and shelf-life. Thus it is not surprising that synthetic, low molecular weight TK inhibitors (TKIs) presently outnumber every other class of HGF/Met therapeutic.

\subsection{Biological HGF/Met Pathway Antagonists}

Biologicals are primarily directed against ligand-receptor binding or related cell-surface events such as receptor clustering, and include [1] truncated HGF isoforms; [2] HGF forms that resist proteolytic activation or its conformational consequences; [3] truncated soluble forms of the Met ectodomain; and [4] neutralizing monoclonal antibodies (mAbs) directed against HGF or Met. 
Early studies revealed that NK2, the truncated protein product of a naturally occurring alternative $H G F$ mRNA transcript, could competitively antagonize growth stimulated by full-length HGF (41). However, the potential anti-oncogenic efficacy of NK2 was later shown to be compromised by its intrinsic motogenic activity, which enhanced HGF-driven metastasis in mouse models (42-46). A longer truncated isoform of full-length HGF known as NK4 has proven to be a complete competitive antagonist of HGF/Met oncogenic signaling in a variety of preclinical models and is now entering human clinical trials (4749). The properties of all HGF/Met agents now in human clinical trials are summarized in Table 1 and available trial results in Table 2.

Antagonistic HGF forms that resist proteolytic activation or its conformational consequences exploit the requirement for proteolytic cleavage that converts pro-HGF to a biologically active heterodimer (50-53). Uncleavable forms of HGF have been engineered by substituting single amino acids in the proteolytic site; such agents suppress Met-driven tumor growth, metastasis and angiogenesis in murine tumor models (54). Related antagonists consisting of two-chain HGF mutants exploit the mechanism by which proteolytic conversion allosterically stabilizes HGF-Met binding to promote kinase activation (55). Structure/function analysis of Met extracellular subdomains has also fostered the development of biological HGF/Met pathway antagonists. Soluble Met Sema domain constructs that sequester HGF and interfere with Met homodimerization suppressed HGF-induced tumor cell migration (56), as well as tumor growth and metastasis in mice (57).

Among HGF/Met-targeted biologicals, the most advanced drug candidates are mAbs directed against either HGF or Met. The majority of these block HGF/Met binding, although at least one anti-Met mAb decreases Met activation by inducing ectodomain shedding and degradation (58). Neutralizing mAbs against human HGF, such as L2G7, AMG102 and SCH900105 (formerly AV299) each potently suppressed the growth of tumor xenografts in mice (59-63). AMG102, currently in phase I and II clinical trials (64), binds to the HGF light chain with $\mathrm{K}_{\mathrm{d}}$ of $0.22 \mathrm{nM}$, blocks HGF-Met binding with an $\mathrm{IC}_{50}$ of $2.1 \mathrm{nM}$, and was well tolerated in humans $(60,65)$. The maximum tolerated dose (MTD) was $20 \mathrm{mg} / \mathrm{kg}$ and adverse events (AEs), which included fatigue, constipation, anorexia, nausea and vomiting, were predominantly low grade (66). AMG102 was maintained in the body with a mean halflife of 15.4 hours (66). SCH900105 is currently in phase I trials: this antibody was also very well tolerated in patients at doses up to $20 \mathrm{mg} / \mathrm{kg}$ and had a similar $15 \mathrm{~h}$ half-life. In its first completed trial, SCH900105 treatment was associated with stable disease (SD) in half of the patients, the longest for 34 weeks (61-63). A humanized, bivalent anti-Met monoclonal antibody, h224G11, inhibits Met phosphorylation and dimerization and blocks proliferation, migration, invasion, morphogenesis and angiogenesis in cell-based studies $(63,67)$. Another anti-Met mAb that blocks ligand binding, MetMab (formerly OA5D5), is an engineered monovalent antibody that has been shown to inhibit tumor growth in animal models by more than 95 percent (68). MetMab has an $\mathrm{IC}_{50}$ of 2.6 to $8.7 \mathrm{nM}$ in intact cells, downregulates constitutively active Met in tumor cell lines (69), and is currently in phase I/II human clinical trials in comparison with erlotinib in patients with NSCLC (64).

\subsection{Small Synthetic Met Kinase Inhibitors}

Most Met TKIs competitively antagonize occupancy of the intracellular ATP binding site, preventing phosphorylation, TK activation and downstream signaling. ARQ197, in contrast, binds to a region of Met outside of the ATP binding site and impairs kinase activation allosterically (70). Preclinical studies show that Met TKIs potently and selectively suppress growth, migration, and/or survival in a variety of tumor-derived cell lines. These agents are in various stages of development; they are discussed here starting with preclinical candidates and ending with those now entering phase III clinical trials. 
Early studies of Met-targeted TKIs, such as SU11274 (IC 50 of $20 \mathrm{nM})(36,71,72)$ and PHA665752 ( $\mathrm{IC}_{50}$ of $\left.9 \mathrm{nM}\right)(24,73)$, established that Met TKIs could potently suppress oncogenesis and provided a platform for improving potency, selectivity and other drug properties. Agents such as RP1040 ( $\mathrm{IC}_{50}$ of $1.3 \mathrm{nM}$ ) (74) and CEP-A ( $\mathrm{IC}_{50}$ of $\left.13 \mathrm{nM}\right)(75)$ are recent preclinical candidates likely to have benefited from those founding reports. RP1040 shows good oral availability and displays a half-life of up to $9 \mathrm{~h}$ in intact cells (74). CEP-A shows sustainable pharmacodynamic (PD) effects in mouse studies, resulting in significant tumor growth inhibition, stable disease (SD) and partial regression (75).

Met TKIs now entering phase I clinical trials to establish safety and tolerability include JNJ-38877605 and PF-04217903. The former shows >1000-fold selectivity for the Met kinase relative to $>200$ related receptor TKs (76), while the latter targets Met as well as anaplastic lymphoma kinase (ALK) (77). Phase I trials with AMG 208 and E7050 are also recruiting patients with advanced solid tumors in which safety, tolerability, PK, and potential PD markers will be evaluated (64). AMG 208 selectively inhibits both liganddependent and ligand-independent Met activation (78) \}, while E7050 targets both Met and VEGFR2 (79). A phase I study of MK8033, which targets Met with $\mathrm{IC}_{50}$ of $1.3 \mathrm{nM}$ and the Met family member Ron, is also underway (64). MP470 inhibits PDGFR, Kit and Met; in preclinical studies, MP470 combined with erlotinib inhibited prostate cancer cell proliferation and tumor xenograft growth (80), and MP470 treatment sensitized glioblastoma cells to radiotherapy in mice (81). A phase I clinical trial of MP470 has shown tolerability of up to $500 \mathrm{mg}$ /day with little toxicity (80). SGX523 showed early promise as a highly selective Met TKI, but phase 1 clinical trials were discontinued after renal toxicity was observed in patients receiving relatively low doses (82). The fact that several other selective Met TKIs do not display this level of renal toxicity suggests that a unique metabolite of SGX523 may have been responsible.

Several Met TKIs are in phase I/II clinical trials that further test safety and efficacy. BMS777607 ( IC $_{50}$ of $3.9 \mathrm{nM}$ ) has completed a phase I/II study in metastatic cancer patients although results are not yet available (83). MGCD265, targeting Met, VEGFR1-3, Ron, and Tie 2 is currently in phase I/II studies in combination with erlotinib or standard of care (SOC) treatments; safety trials have shown a half-life of 20-30 hours with no grade 2 or higher AEs $(84,85)$. MK2461 has completed phase I/II trials and showed a half-life of approximately 6 hours, few AEs above grade 1 (which included anorexia, fatigue and nausea), and a best response of SD for six treatment cycles $(86,87)$.

Foretinib (GSK1363089; formerly XL880) and ARQ197 have shown promising results in multiple phase II trials. Foretinib targets Met and VEGFR2; trials have shown a half-life of 60 hours at the maximum dose of $240 \mathrm{mg} / \mathrm{day}$. The most common AEs were grade 1 or 2 fatigue, hypertension, nausea, anorexia and vomiting. Several studies have shown SD for at least 10 months and some patients have experienced $>20$ percent reduction in tumor size (88-91). ARQ197 is reported to be highly selective for Met and has an $\mathrm{IC}_{50}$ of $50 \mathrm{nM}$ in vitro (86). Although its mechanism of action is not yet completely defined, this compound may represent a new class of low molecular weight TKI (70). Current phase II clinical trials compare ARQ197 with TKIs against other targets, although results are not yet available (70).

Met TKIs furthest in development include XL184 and PF02341066, both now entering phase III clinical trials. XL184 targets Met, VEGFR2, and Ret and has a half-life of 80-90 hours (92). On average, patients show SD greater than 3 months with several up to 6 months while on treatment (93). A current phase III trial investigates XL184 as a first line treatment, compared to placebo, in patients with medullary thyroid cancer (64). PF-02341066, which has greater Met selectivity relative to PF-04217903 (94), is currently recruiting for phase I, 
II and III clinical trials (64). It is well tolerated up to the MTD of $240 \mathrm{mg} /$ day and preclinical studies indicate it is highly effective against the product of the $E M L 4-A L K$ translocation found in a subset of NSCLC patients $(95,96)$.

\section{Advanced Trials and Future Directions: Patient Selection, Pharmacodynamic Markers and Combination Treatments}

An important challenge facing the effective use of molecularly targeted therapeutics is identifying those patients most likely to benefit from treatment. Preclinical studies of several Met-targeted agents have included investigating their effectiveness against known Met mutants; for example, PF02341066 is more effective than PF-04217903 against the Y1230C mutation (94). In a current phase II trial of foretinib, PRC patients with germline or somatic MET mutations, MET gene amplification or trisomy of chromosome 7 are being compared to those without these features but otherwise histologically similar tumor phenotype (8891). Future trials are likely to follow this trend where possible.

Another common patient selection strategy has been the use of immunohistochemical analysis (IHC) of tumor sections, because these specimens are routinely obtained for standard pathological diagnosis. However, few antibodies currently available work well in IHC because recognition is compromised by tissue fixation and paraffin-embedding. Only recently has a mAb targeting the extracellular domain, MET4, shown high sensitivity and low background in IHC (97). Although IHC provides important spatial and morphological information, quantitative comparisons are problematic. As an alternative, immunoassays of tissue extracts can provide precise, absolute measurements of Met content and phosphorylation state, but lack morphological information and typically require frozen tissue samples.

Reliable PD markers have always been important to drug development, and are even more so now that combinations of highly selective targeted drugs are considered. Several ongoing clinical trials of Met-targeted drugs include PD marker studies. Plasma concentrations of soluble Met (sMet), soluble VEGFR2 (sVEGFR2), VEGF, PIGF, and EPO changed significantly during foretinib dosing $(89,90,98)$. Plasma HGF, VEGF, sMet, sVEGFR2 were also examined in response to MGCD265 treatment $(84,85)$; both studies suggest that these may become useful PD markers. In a clinical study of XL184, modulation of plasma VEGFA, sMet, sVEGFR2, sKIT, and PIGF were also consistent with on-target drug effects (99). Studies have also linked PD markers to clinical response, such as plasma HGF levels during XL184 treatment (100), similar to changes in HGF levels reported in a study of RCC patients treated with sorafenib (101) or pazobanib (102).

The emergence of primary and acquired resistance to TKIs from pre-existing or de novo mutations, respectively, must be addressed in the design of future clinical studies. Strategies to overcome this problem include: [1] selecting treatments based on the presence of known susceptibility factors; [2] combining different classes of inhibitors of a single pathway; [3] combining therapeutics against multiple pathways; and [4] combining targeted therapeutics with SOC treatments. An example of the first strategy is the use of MK8033 in patients with MET amplification or constitutive Met activation, with the hope of confirming predictive preclinical results (103). Combinations of HGF/Met mAbs and Met TKIs, as in the second strategy, are planned for future trials. The third design is being used in several current trials of Met antagonists: ARQ197, MGCD265, XL184, and PF02341066 are being used in combination with Erlotinib for the treatment of NSCLC and ARQ197 is also being tested in combination with Sorafenib for the treatment of advanced solid tumors (64). Adding Mettargeted therapies to first-line therapies targeting other pathways may be particularly useful for cancers where Met may participate in the acquisition of resistance and thereby 
dramatically increase the risk of metastasis. MET gene amplification was detected in $22 \%$ of lung cancer specimens that had acquired resistance to gefitinib or erlotinib, and treatment of a lung cancer cell line that had acquired gefitinib resistance through $M E T$ amplification with a Met-targeted TKI restored gefitinib sensitivity (104). Several studies of Met inhibitors in combination with erlotinib for the treatment of NSCLC are now under way with promising results (23). Examples of the fourth strategy are also abundant: trials combining AMG102, ARQ197, MP470, MGCD265, XL184, or PF02341066 with SOC treatments -

chemotherapeutic agents or radiotherapy, are also currently underway (64). Again, preclinical studies such as those combining AMG102 with temozolomide or docetaxel for the treatment of gastric, prostate, and colorectal cancers provide a sound rationale and guide initial trial design (59).

In closing, the wealth of basic knowledge about HGF/Met biology has enabled an accurate assessment of the pathway's oncogenic potential and provided the insight needed to develop potent and selective inhibitors and use them with relative safety in humans. Patient selection, of primary importance, will advance as more robust methods are developed to analyze the many known potential diagnostic biomarkers of pathway activity. Methods that rely on DNA or RNA (e.g. detecting $M E T$ gene amplification or mutation) are now faster and more sensitive than those available for quantitating Met protein content and phosphorylation state, but efforts to improve both are underway. Similarly, the need for PD markers that track drug effect and patient response is recognized and clinical PD marker studies currently underway reveal solid candidates. Finally, although the complexity of cancer and the risk of acquired resistance may limit the use of HGF/Met molecular therapeutics as single agents to subgroups of patients, much evidence suggests that pathway involvement is widespread and critical for metastasis. Thus for HGF/Met pathway inhibitors in particular, combinatorial phase II trials with small, carefully selected patient groups may be the most expedient path to more effective cancer treatment.

\section{Acknowledgments}

Web site addresses are provided as an informational resource, not as an endorsement of any product or manufacturer. This work was supported by the Intramural Research Program of the NIH, National Cancer Institute, Center for Cancer Research.

\section{References}

1. Peschard P, Park M. From Tpr-Met to Met tumorigenesis and tubes. Oncogene. 2007; 26:12761285. [PubMed: 17322912]

2. Furge KA, Zhang YW, Vande Woude GF. Met receptor tyrosine kinase: enhanced signaling through adapter proteins. Oncogene. 2000; 19:5582-5589. [PubMed: 11114738]

3. Yu J, Miehlke S, Ebert MP, et al. Frequency of TPR-MET rearrangement in patients with gastric carcinoma and in first-degree relatives. Cancer. 2000; 88:1801-1806. [PubMed: 10760755]

4. Bottaro DP, Rubin JS, Faletto DL, et al. Identification of the hepatocyte growth factor receptor as the c-met proto-oncogene product. Science. 1991; 251:802-804. [PubMed: 1846706]

5. Birchmeier C, Birchmeier W, Gherardi E, Vande Woude GF. Met, metastasis, motility and more. Nat Rev Mol Cell Biol. 2003; 4:915-925. [PubMed: 14685170]

6. Zhang YW, Vande Woude GF. HGF/SF-met signaling in the control of branching morphogenesis and invasion. J Cell Biochem. 2003; 88:408-417. [PubMed: 12520544]

7. Rosario M, Birchmeier W. How to make tubes: signaling by the Met receptor tyrosine kinase. Trends Cell Biol. 2003; 13:328-335. [PubMed: 12791299]

8. Corso S, Comoglio PM, Giordano S. Cancer therapy: can the challenge be MET? Trends Mol Med. 2005; 11:284-292. [PubMed: 15949770]

9. Matsumoto K, Nakamura T. Hepatocyte growth factor: Renotropic role and potential therapeutics for renal diseases. Kidney International. 2001; 59:2023-2038. [PubMed: 11380804] 
10. Morishita R, Aoki M, Hashiya N, et al. Therapeutic angiogenesis using hepatocyte growth factor (HGF). Curr Gene Ther. 2004; 4:199-206. [PubMed: 15180586]

11. Huh CG, Factor VM, Sanchez A, Uchida K, Conner EA, Thorgeirsson SS. Hepatocyte growth factor/c-met signaling pathway is required for efficient liver regeneration and repair. Proc Natl Acad Sci U S A. 2004; 101:4477-4482. [PubMed: 15070743]

12. Borowiak M, Garratt AN, Wustefeld T, Strehle M, Trautwein C, Birchmeier C. Met provides essential signals for liver regeneration. Proc Natl Acad Sci U S A. 2004; 101:10608-10613. [PubMed: 15249655]

13. Liu Y. Renal fibrosis: new insights into the pathogenesis and therapeutics. Kidney Int. 2006; 69:213-217. [PubMed: 16408108]

14. Weidner KM, Sachs M, Birchmeier W. The Met receptor tyrosine kinase transduces motility, proliferation, and morphogenic signals of scatter factor/hepatocyte growth factor in epithelial cells. J Cell Biol. 1993; 121:145-154. [PubMed: 8384622]

15. Zioncheck TF, Richardson L, Liu J, et al. Sulfated oligosaccharides promote hepatocyte growth factor association and govern its mitogenic activity. J Biol Chem. 1995; 270:16871-16878. [PubMed: 7622503]

16. Schwall RH, Chang LY, Godowski PJ, et al. Heparin induces dimerization and confers proliferative activity onto the hepatocyte growth factor antagonists NK1 and NK2. J Cell Biol. 1996; 133:709-718. [PubMed: 8636243]

17. Hartmann G, Prospero T, Brinkmann V, et al. Engineered mutants of HGF/SF with reduced binding to heparan sulphate proteoglycans, decreased clearance and enhanced activity in vivo. Curr Biol. 1998; 8:125-134. [PubMed: 9443912]

18. Sakata H, Stahl SJ, Taylor WG, et al. Heparin binding and oligomerization of hepatocyte growth factor/scatter factor isoforms. Heparan sulfate glycosaminoglycan requirement for Met binding and signaling. J Biol Chem. 1997; 272:9457-9463. [PubMed: 9083085]

19. Lyon M, Deakin JA, Lietha D, Gherardi E, Gallagher JT. The interactions of hepatocyte growth factor/scatter factor and its NK1 and NK2 variants with glycosaminoglycans using a modified gel mobility shift assay. Elucidation of the minimal size of binding and activatory oligosaccharides. $\mathrm{J}$ Biol Chem. 2004; 279:43560-43567. [PubMed: 15292253]

20. Mohammadi M, Olsen SK, Goetz R. A protein canyon in the FGF-FGF receptor dimer selects from an a la carte menu of heparan sulfate motifs. Curr Opin Struct Biol. 2005; 15:506-516. [PubMed: 16154740]

21. Rubin JS, Day RM, Breckenridge D, et al. Dissociation of Heparan Sulfate and Receptor Binding Domains of Hepatocyte Growth Factor Reveals that Heparan Sulfate-c-Met Interaction Facilitates Signaling. J Biol Chem. 2001; 276:32977-32983. [PubMed: 11435444]

22. 2009. http://www.vai.org/vari/metandcancer

23. Hammerman PS, Janne PA, Johnson BE. Resistance to Epidermal Growth Factor Receptor Tyrosine Kinase Inhibitors in Non-Small Cell Lung Cancer. Clin Cancer Res. 2009; 15:75027509. [PubMed: 20008850]

24. Smolen GA, Sordella R, Muir B, et al. Amplification of MET may identify a subset of cancers with extreme sensitivity to the selective tyrosine kinase inhibitor PHA-665752. PNAS. 2006; 103:2316-2321. [PubMed: 16461907]

25. Lengyel E, Prechtel D, Resau JH, et al. C-Met overexpression in node-positive breast cancer identifies patients with poor clinical outcome independent of Her2/neu. Int J Cancer. 2005; 113:678-682. [PubMed: 15455388]

26. Schmidt C, Bladt F, Goedecke S, et al. Scatter factor/hepatocyte growth factor is essential for liver development. Nature. 1995; 373:699-702. [PubMed: 7854452]

27. Dharmawardana PG, Giubellino A, Bottaro DP. Hereditary papillary renal carcinoma type I. Curr Mol Med. 2004; 4:855-868. [PubMed: 15579033]

28. Ma PC, Maulik G, Christensen J, Salgia R. c-Met: structure, functions and potential for therapeutic inhibition. Cancer Metastasis Rev. 2003; 22:309-325. [PubMed: 12884908]

29. Lengyel E, Sawada K, Salgia R. Tyrosine kinase mutations in human cancer. Curr Mol Med. 2007; 7:77-84. [PubMed: 17311534] 
30. Schmidt L, Junker K, Nakaigawa N, et al. Novel mutations of the MET proto-oncogene in papillary renal carcinomas. Oncogene. 1999; 18:2343-2350. [PubMed: 10327054]

31. Miller M, Ginalski K, Lesyng B, Nakaigawa N, Schmidt L, Zbar B. Structural basis of oncogenic activation caused by point mutations in the kinase domain of the MET proto-oncogene: modeling studies. Proteins. 2001; 44:32-43. [PubMed: 11354004]

32. Bardelli A, Longati P, Gramaglia D, et al. Uncoupling signal transducers from oncogenic MET mutants abrogates cell transformation and inhibits invasive growth. Proc Natl Acad Sci U S A. 1998; 95:14379-14383. [PubMed: 9826708]

33. Giordano S, Maffe A, Williams TA, et al. Different point mutations in the met oncogene elicit distinct biological properties. FASEB J. 2000; 14:399-406. [PubMed: 10657996]

34. Michieli P, Basilico C, Pennacchietti S, et al. Mutant Met-mediated transformation is liganddependent and can be inhibited by HGF antagonists. Oncogene. 1999; 18:5221-5231. [PubMed: 10498872]

35. Graveel CR, London CA, Vande Woude GF. A mouse model of activating Met mutations. Cell Cycle. 2005; 4:518-520. [PubMed: 15738649]

36. Ma PC, Jagadeeswaran R, Jagadeesh S, et al. Functional Expression and Mutations of c-Met and Its Therapeutic Inhibition with SU11274 and Small Interfering RNA in Non-Small Cell Lung Cancer. Cancer Research. 2005; 65:1479-1488. [PubMed: 15735036]

37. Ma PC, Kijima T, Maulik G, et al. c-MET mutational analysis in small cell lung cancer: novel juxtamembrane domain mutations regulating cytoskeletal functions. Cancer Res. 2003; 63:62726281. [PubMed: 14559814]

38. Kong-Beltran M, Seshagiri S, Zha J, et al. Somatic mutations lead to an oncogenic deletion of met in lung cancer. Cancer Res. 2006; 66:283-289. [PubMed: 16397241]

39. Corso S, Migliore C, Ghiso E, De RG, Comoglio PM, Giordano S. Silencing the MET oncogene leads to regression of experimental tumors and metastases. Oncogene. 2008; 27:684-693. [PubMed: 17684486]

40. Pennacchietti S, Michieli P, Galluzzo M, Mazzone M, Giordano S, Comoglio PM. Hypoxia promotes invasive growth by transcriptional activation of the met protooncogene. Cancer Cell. 2003; 3:347-361. [PubMed: 12726861]

41. Chan AML, Rubin JS, Bottaro DP, Hirschfield DW, Chedid M, Aaronson SA. Identification of a competitive HGF antagonist encoded by an alternative transcript. Science. 1991; 254:1382-1385. [PubMed: 1720571]

42. Stahl SJ, Wingfield PT, Kaufman JD, et al. Functional and biophysical characterization of recombinant human hepatocyte growth factor isoforms produced in Escherichia coli. Biochemical Journal. 1997; 326:763-772. [PubMed: 9307026]

43. Montesano R, Soriano JV, Malinda KM, et al. Differential effects of hepatocyte growth factor isoforms on epithelial and endothelial tubulogenesis. Cell Growth and Differentiation. 1998; 9:355-365. [PubMed: 9607557]

44. Otsuka T, Horiguchi N, Kanda D, et al. Overexpression of NK2 inhibits liver regeneration after partial hepatectomy in mice. World J Gastroenterol. 2005; 11:7444-7449. [PubMed: 16437714]

45. Toyoda M, Takayama H, Horiguchi N, et al. Overexpression of hepatocyte growth factor/scatter factor promotes vascularization and granulation tissue formation in vivo. FEBS Lett. 2001; 509:95-100. [PubMed: 11734213]

46. Yu Y, Merlino G. Constitutive c-Met signaling through a nonautocrine mechanism promotes metastasis in a transgenic transplantation model. Cancer Res. 2002; 62:2951-2956. [PubMed: 12019177]

47. Matsumoto K, Nakamura T. Mechanisms and significance of bifunctional NK4 in cancer treatment. Biochemical and Biophysical Research Communications. 2005; 333:316-327. [PubMed: 15950947]

48. Toschi L, Janne PA. Single-agent and combination therapeutic strategies to inhibit hepatocyte growth factor/MET signaling in cancer. Clin Cancer Res. 2008; 14:5941-5946. [PubMed: 18829470]

49. 2009. http://venturevaluation.com/vv_web/en/node/246 
50. Gak E, Taylor WG, Chan AM, Rubin JS. Processing of hepatocyte growth factor to the heterodimeric form is required for biological activity. FEBS Lett. 1992; 311:17-21. [PubMed: 1383032]

51. Hartmann G, Naldini L, Weidner KM, et al. A functional domain in the heavy chain of scatter factor/hepatocyte growth factor binds the c-Met receptor and induces cell dissociation but not mitogenesis. Proc Natl Acad Sci U S A. 1992; 89:11574-11578. [PubMed: 1280830]

52. Lokker NA, Mark MR, Luis EA, et al. Structure-function analysis of hepatocyte growth factor: identification of variants that lack mitogenic activity yet retain high affinity receptor binding. EMBO J. 1992; 11:2503-2510. [PubMed: 1321034]

53. Naka D, Ishii T, Yoshiyama Y, et al. Activation of hepatocyte growth factor by proteolytic conversion of a single chain form to a heterodimer. J Biol Chem. 1992; 267:20114-20119. [PubMed: 1328193]

54. Mazzone M, Basilico C, Cavassa S, et al. An uncleavable form of pro-scatter factor suppresses tumor growth and dissemination in mice. J Clin Invest. 2004; 114:1418-1432. [PubMed: 15545993]

55. Kirchhofer D, Lipari MT, Santell L, et al. Utilizing the activation mechanism of serine proteases to engineer hepatocyte growth factor into a Met antagonist. Proc Natl Acad Sci U S A. 2007; 104:5306-5311. [PubMed: 17372204]

56. Kong-Beltran M, Stamos J, Wickramasinghe D. The Sema domain of Met is necessary for receptor dimerization and activation. Cancer Cell. 2004; 6:75-84. [PubMed: 15261143]

57. Michieli P, Mazzone M, Basilico C, et al. Targeting the tumor and its microenvironment by a dualfunction decoy Met receptor. Cancer Cell. 2004; 6:61-73. [PubMed: 15261142]

58. Petrelli A, Circosta P, Granziero L, et al. Ab-induced ectodomain shedding mediates hepatocyte growth factor receptor down-regulation and hampers biological activity. Proc Natl Acad Sci U S A. 2006; 103:5090-5095. [PubMed: 16547140]

59. Kim KJ, Wang L, Su YC, et al. Systemic anti-hepatocyte growth factor monoclonal antibody therapy induces the regression of intracranial glioma xenografts. Clin Cancer Res. 2006; 12:12921298. [PubMed: 16489086]

60. Burgess T, Coxon A, Meyer S, et al. Fully human monoclonal antibodies to hepatocyte growth factor with therapeutic potential against hepatocyte growth factor/c-Met-dependent human tumors. Cancer Res. 2006; 66:1721-1729. [PubMed: 16452232]

61. Meetze AK, Boudrow A, Connoly K, Huang R, Rideout W, Gyuris J, Han M. Anti-tumor activity of SCH 900105AV299), an anti-HGF antibody in non-small cell lung cancer models. AACR-NCIEORTC - international conference - molecular target and cancer therapeutics, C173. 2009

62. Meetze AK, COnnoly K, Boudrow A, Venkataraman S, Medicherla S, Gyuris J, Han M. Preclinical efficacy and pharmacodynamics of SCH 900105 (AV-299) and anti-HGF antibody in an intracranial glioblastoma. AACR-NCI-EORTC - international conference - molecular target and cancer therapeutics, C181. 2009

63. Ramanathan RK, Paymo CF, Papadopoulos PK, et al. A Phase 1 first-in-human study of SCH 900105, an antihepatocyte growth factor (HGF) monoclonal antibody, in subjects with advanced solid cancer. AACR Nov 2009 Boston, Abstract A100.

64. 2009. www.clinicaltrials.govwww.clinicaltrials.gov

65. Giordano S. Rilotumumab, a mAb against human hepatocyte growth factor for the treatment of cancer. Curr Opin Mol Ther. 2009; 11:448-455. [PubMed: 19649990]

66. Gordon MS, Mendelson DS, Sweeney C, et al. Interim results from a first-in-human study with AMG102, a fully human monoclonal antibody that neutralizes hepatocyte growth factor (HGF), the ligand to c-Met receptor, in patients (pts) with advanced solid tumors. J Clin Oncol (Meeting Abstracts). 2007; 25:3551.

67. Corvaïa N, Gonzalez A, Boute N, Beau-Larvor C, Fabre-Lafay S, Géronimi F, Broussas Lepecquet AM, Robert A, Wurch T, Haeuw JF, Bailly C, Goetsch L. First bivalent fully antagonist anti-cMet antibody targeting the c-Met receptor: I) in vitro mechanism of action. 2009 AACR Annual Meeting. 2009; 835

68. Martens T, Schmidt N-O, Eckerich C, et al. Inhibition of intracerebral glioblastoma growth by treatment with a novel one-armed anti-Met antibody. 2005 
69. Cheng JQ, Lindsley CW, Cheng GZ, Yang H, Nicosia SV. The Akt/PKB pathway: molecular target for cancer drug discovery. Oncogene. 2005; 24:7482-7492. [PubMed: 16288295]

70. Gu X, Wang C, Yu Y, et al. Inhibition of HGF/c-Met pathway by ARQ 197: Characterization of pharmacodynamic markers in vitro and in vivo. AACR Nov 2009 Boston, Abstract 1748. 2009

71. Sattler M, Pride YB, Ma P, et al. A novel small molecule met inhibitor induces apoptosis in cells transformed by the oncogenic TPR-MET tyrosine kinase. Cancer Res. 2003; 63:5462-5469. [PubMed: 14500382]

72. Berthou S, Aebersold DM, Schmidt LS, et al. The Met kinase inhibitor SU11274 exhibits a selective inhibition pattern toward different receptor mutated variants. Oncogene. 2004; 23:53875393. [PubMed: 15064724]

73. Christensen JG, Schreck R, Burrows J, et al. A Selective Small Molecule Inhibitor of c-Met Kinase Inhibits c-Met-Dependent Phenotypes in Vitro and Exhibits Cytoreductive Antitumor Activity in Vivo. Cancer Research. 2003; 63:7345-7355. [PubMed: 14612533]

74. Viswanadha S, Muthuppalaniappan M, Varanasi KVS, et al. Pharacological and pharmacokinetic characterization of RP1040, a novle and potent c-Met tyrosine kinase inhibitor. AACR Nov 2009 Boston, Abstract C212. 2009

75. Miknyoczki SJ, Underiner T, Aimone T, et al. Identification of orally active small molecule c-Met inhibitors. AACR Nov 2009 Boston, Abstract A1747. 2009

76. Eder JP, Vande Woude GF, Boerner SA, LoRusso PM. Novel therapeutic inhibitors of the c-Met signaling pathway in cancer. Clin Cancer Res. 2009; 15:2207-2214. [PubMed: 19318488]

77. Sattler M, Salgia R. The MET axis as a therapeutic target. 2009:109-118.

78. 2009. http://www.amgen.com/science/pipe_amg_208.html

79. Nakagawa T, Tohyama O, Yamaguchi A, et al. E7050: A dual c-Met and VEGFR-2 tyrosine kinase inhibitor promotes tumor regression and prolongs survival in mouse xenograft models. Cancer Sci. 2009

80. Qi W, Cooke LS, Stejskal A, et al. MP470, a novel receptor tyrosine kinase inhibitor, in combination with Erlotinib inhibits the HER family/PI3K/Akt pathway and tumor growth in prostate cancer. BMC Cancer. 2009; 9:142. [PubMed: 19432987]

81. Welsh P, Mahadevan D, Bearss D, Stea B. Sensitization of a Glioblastoma Multiforme (GBM) Cell Line by MP470: A Novel c-Met Antagonist. International Journal of Radiation Oncology. 2007; Volume 69:S100.

82. 2009. www.sgxpharma.com

83. Schroeder GM, An Y, Cai ZW, et al. Discovery of N-(4-(2-Amino-3-chloropyridin-4-yloxy)-3fluorophenyl)-4-ethoxy-1-(4-fluor ophenyl)-2-oxo-1,2-dihydropyridine-3-carboxamide (BMS-777607), a Selective and Orally Efficacious Inhibitor of the Met Kinase Superfamily. J Med Chem. 2009; 52:1251-1254. [PubMed: 19260711]

84. Hong D, LoRusso P, Kurzrock R, et al. Phase I study of MGCD265 administered intermittently to patients with advanced malignancies (Study 265-102). J Clin Oncol (Meeting Abstracts). 2009; 27:e14516.

85. Kollmannsberger CK, Hurwitz H, Vlahovic G, et al. Phase I study of daily administration of MGCD265 to patients with advanced malignancies (Study 265-101). J Clin Oncol (Meeting Abstracts). 2009; 27:e14525.

86. Jeay S, Munshi N, Hill J, et al. ARQ 197, a highly selective small molecule inhibitor of c-Met, with selective antitumor properties in a broad spectrum of human cancer cells. AACR Meeting Abstracts. 2007; 2007:2369.

87. Li Y, Chen D, Zhou W, et al. Broad spectrum anti-cancer activity of ARQ 197, a highly selective oral c-Met Inhibitor, in multiple xenograft models. AACR Meeting Abstracts. 2007; 2007:2216.

88. Ross RW, Stein M, Sarantopoulos J, et al. A phase II study of the c-Met RTK inhibitor XL880 in patients (pts) with papillary renal-cell carcinoma (PRC). J Clin Oncol (Meeting Abstracts). 2007; 25:15601.

89. Srinivasan R, Choueiri TK, Vaishampayan U, et al. A phase II study of the dual MET/VEGFR2 inhibitor XL880 in patients (pts) with papillary renal carcinoma (PRC). J Clin Oncol (Meeting Abstracts). 2008; 26:5103. 
90. Jhawer M, Kindler HL, Wainberg Z, et al. Assessment of two dosing schedules of GSK1363089 (GSK089), a dual MET/VEGFR2 inhibitor, in metastatic gastric cancer (GC): Interim results of a multicenter phase II study. J Clin Oncol (Meeting Abstracts). 2009; 27:4502.

91. Eder JP, Heath E, Appleman L, et al. Phase I experience with c-MET inhibitor XL880 administered orally to patients (pts) with solid tumors. J Clin Oncol (Meeting Abstracts). 2007; 25:3526.

92. Salgia R, Hong DS, Camacho LH, et al. A phase I dose-escalation study of the safety and pharmacokinetics (PK) of XL184, a VEGFR and MET kinase inhibitor, administered orally to patients (pts) with advanced malignancies. J Clin Oncol (Meeting Abstracts). 2007; 25:14031.

93. Salgia R, Sherman S, Hong DS, et al. A phase I study of XL184, a RET, VEGFR2, and MET kinase inhibitor, in patients (pts) with advanced malignancies, including pts with medullary thyroid cancer (MTC). J Clin Oncol (Meeting Abstracts). 2008; 26:3522.

94. Timofeevski SL, McTigue MA, Ryan K, et al. Enzymatic characterization of c-Met receptor tyrosine kinase oncogenic mutants and kinetic studies with aminopyridine and triazolopyrazine inhibitors. Biochemistry. 2009; 48:5339-5349. [PubMed: 19459657]

95. 2009. www.pfizer.comwww.pfizer.com

96. Shaw AT, Yeap BY, Mino-Kenudson M, et al. Clinical features and outcome of patients with nonsmall-cell lung cancer who harbor EML4-ALK. J Clin Oncol. 2009; 27:4247-4253. [PubMed: 19667264]

97. Knudsen BS, Zhao P, Resau J, et al. A Novel Multipurpose Monoclonal Antibody for Evaluating Human c-met Expression in Preclinical and Clinical Settings. Appl Immunohistochem Mol Morphol. 2008

98. Cecchi F, Liu L, Gagnon RC, et al. ShedMET (sMet), VEGFA, and sVEGFR2 are markers of foretinib treatment in metastatic gastric cancer patients. AACR-NCI-EORTC - international conference - molecular target and cancer therapeutics, B210. 2009

99. DePrimo S, Wu B, Huang S, et al. Correlative tumor molecular profiling and plasma biomarker analysis in a phase II study of XL184 in patients with progressive or recurrent glioblastoma multiforme (GBM). J Clin Oncol (Meeting Abstracts). 2009; 27:2049.

100. Muller T, DePrimo S, McGrath G, et al. Pharmacodynamic and correlative biomarker analyses in clinical trials of XL184, and oral, potent inhibitor of MET, VEGFR2, and RET. AACR-NCIEORTC - international conference - molecular target and cancer therapeutics, B269. 2009

101. Pena C, Shan M, Bukowski RM, Escudier B, Lathia C. Plasma biomarkers predicting outcome in patients with advanced RCC: Results from the sorafenib phase II TARGET trial. AACR Nov 2009 Boston, Abstract A36. 2009

102. Heymach JV, Tran TH, Fritsche HA, et al. Lower baseline levels of plasm hepatocyet growth factor, IL-6, IL08 are correlated with greater tumor shrinkage in renal cell carcinoma patients treated with pazopanib. AACR Nov 2009 Boston, Abstract A11. 2009

103. Harrington EA, Chan GK, Chenard M, Dahlberg WK, Davis LJ, Deshmukh SV, Dinsmore C, Efferson C, Hang G, Hatch H, Kohl CH, Kunii K, Lu W, Lutterbach B, Majumder KP, Northrup A, Qu X, Reilly JF, Rosenstein C, Szewczak AA, Tammam J, Ware C, Zheng Q, Pan B. MK-8033, a selective c-Met / Ron inhibitor, suppresses tumor cell growth in vitro and in vivo. 2009 AACR Annual Meeting, 1751. 2009

104. Engelman JA, Zejnullahu K, Mitsudomi T, et al. MET amplification leads to gefitinib resistance in lung cancer by activating ERBB3 signaling. Science. 2007; 316:1039-1043. [PubMed: 17463250]

105. Eder JP, Appleman L, Heath E, et al. A phase I study of a novel spectrum selective kinase inhibitor (SSKI), XL880, administered orally in patients (pts) with advanced solid tumors (STs). J Clin Oncol (Meeting Abstracts). 2006; 24:3041.

106. Jhawer MP, Kindler HL, Wainberg ZA, et al. Preliminary activity of XL880, a dual MET/ VEGFR2 inhibitor, in MET amplified poorly differentiated gastric cancer (PDGC): Interim results of a multicenter phase II study. J Clin Oncol (Meeting Abstracts). 2008; 26:4572.

107. Camacho LH, Moulder SL, LoRusso PM, et al. First in human phase I study of MK-2461, a small molecule inhibitor of c-Met, for patients with advanced solid tumors. J Clin Oncol (Meeting Abstracts). 2008; 26:14657. 
108. Mita MM, Tolcher A, Gordon MS, et al. A phase Ib dose-escalation study of orally administered MP-470, a multi-kinase inhibitor and supressor of Rad51, in combination with carboplatin doublet containing regimens shows activity in highly refractory solid tumor patients. J Clin Oncol (Meeting Abstracts). 2009; 27:e13511.

109. Jessen KA, Froning KJ, Felce JD. In vitro and in vivo antitumor activities of SGX523, a novel MET inhibitor. AACR-NCI-EORTC - international conference - molecular target and cancer therapeutics, B233. 2007

110. Gessert SF, Aubol BE, Do TH, Hendle J. Selective inhibition of MET protein receptor tyrosine kinase by SGX253. AACR-NCI-EORTC - international conference - molecular target and cancer therapeutics, C198. 2007

111. Sorensen AG, Jenning D, Wang M, et al. Use of neurovascular imaging in GBM patients (pts) to quantify early physiologic changes after treatment with XL184, an inhibitor of multiple receptor tyrosine kinases: Results from a phase II study. J Clin Oncol (Meeting Abstracts). 2009; 27:2048.

112. De Groot JF, Prados M, Urquhart T, et al. A phase II study of XL184 in patients (pts) with progressive glioblastoma multiforme (GBM) in first or second relapse. J Clin Oncol (Meeting Abstracts). 2009; 27:2047.

113. Kwak EL, Camidge DR, Clark J, et al. Clinical activity observed in a phase I dose escalation trial of an oral c-met and ALK inhibitor, PF-02341066. J Clin Oncol (Meeting Abstracts). 2009; 27:3509.

114. Liu G, LoRusso PM, Goncalves P, et al. Phase I pharmacokinetic (PK) and pharmacodynamic (PD) study of PF-00337210, a highly selective VEGFR inhibitor. J Clin Oncol (Meeting Abstracts). 2009; 27:3519. 


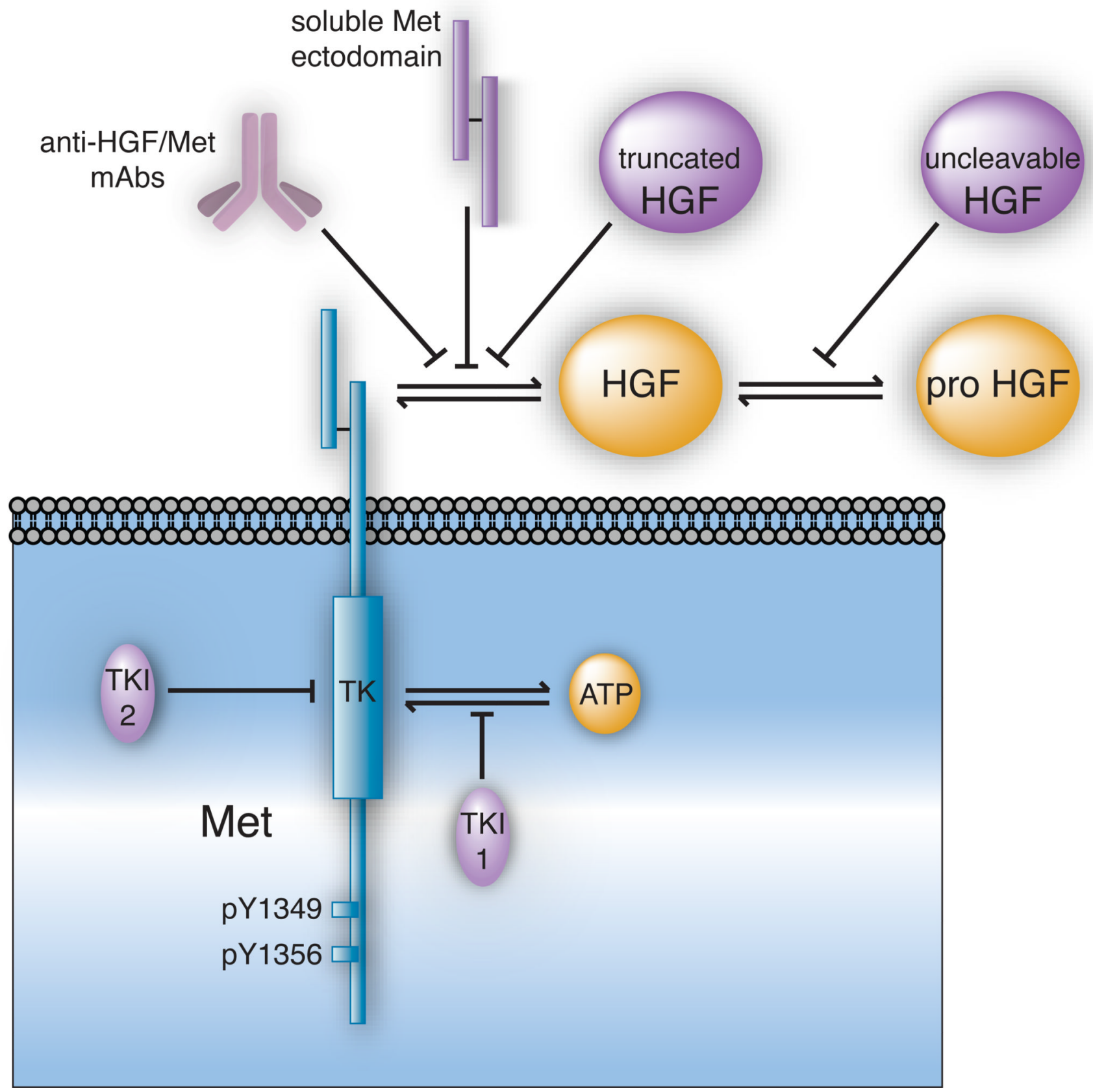

Figure 1. Methods of Blocking the HGF/Met Signaling Pathway

Oncogenic signaling by cellular Met (in blue) and its natural ligands (in yellow) can be antagonized by several distinct inhibitor types (in violet). The intracellular tyrosine kinase (TK) domain and carboxyl terminal docking sites (Y1349 and Y1356) of Met are noted. Pathway inhibitors can be divided broadly into two subtypes (1) biological antagonists of HGF activation and HGF/Met binding, and (2) Met TK inhibitors (TKIs). Biological agents acting outside of the target cell (1) include anti-HGF and anti-Met mAbs, soluble Met ectodomain constructs and truncated HGF isoforms (all of which interfere with HGF/Met binding) and uncleavable forms of HGF (which competitively displace pro-HGF from its activators). Agents acting within the cell (2) include TKIs that competitively displace ATP 
from its TK domain binding site (TKI-1) and those which bind outside of the ATP binding pocket and inhibit Met TK activation allosterically (TKI-2). 


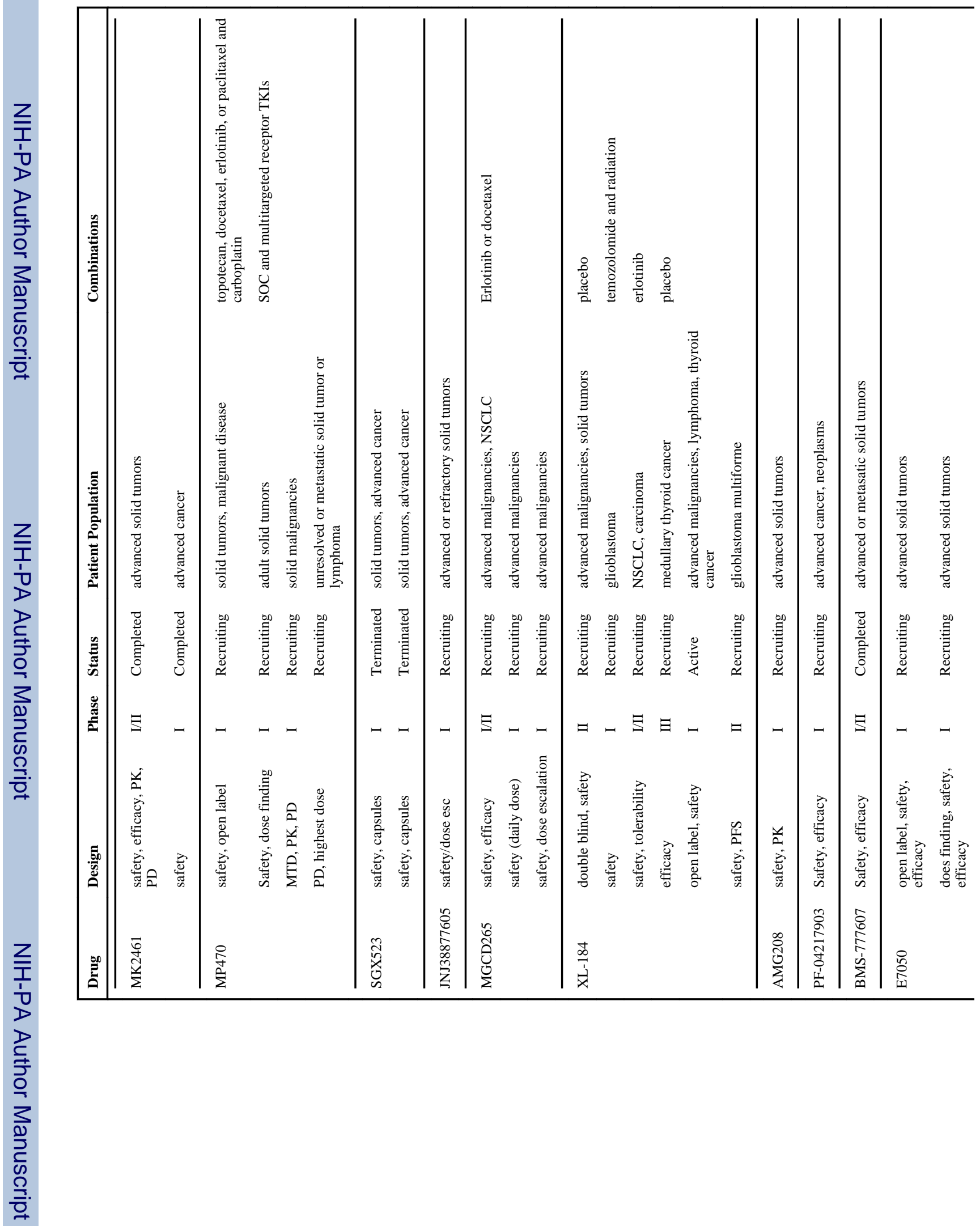




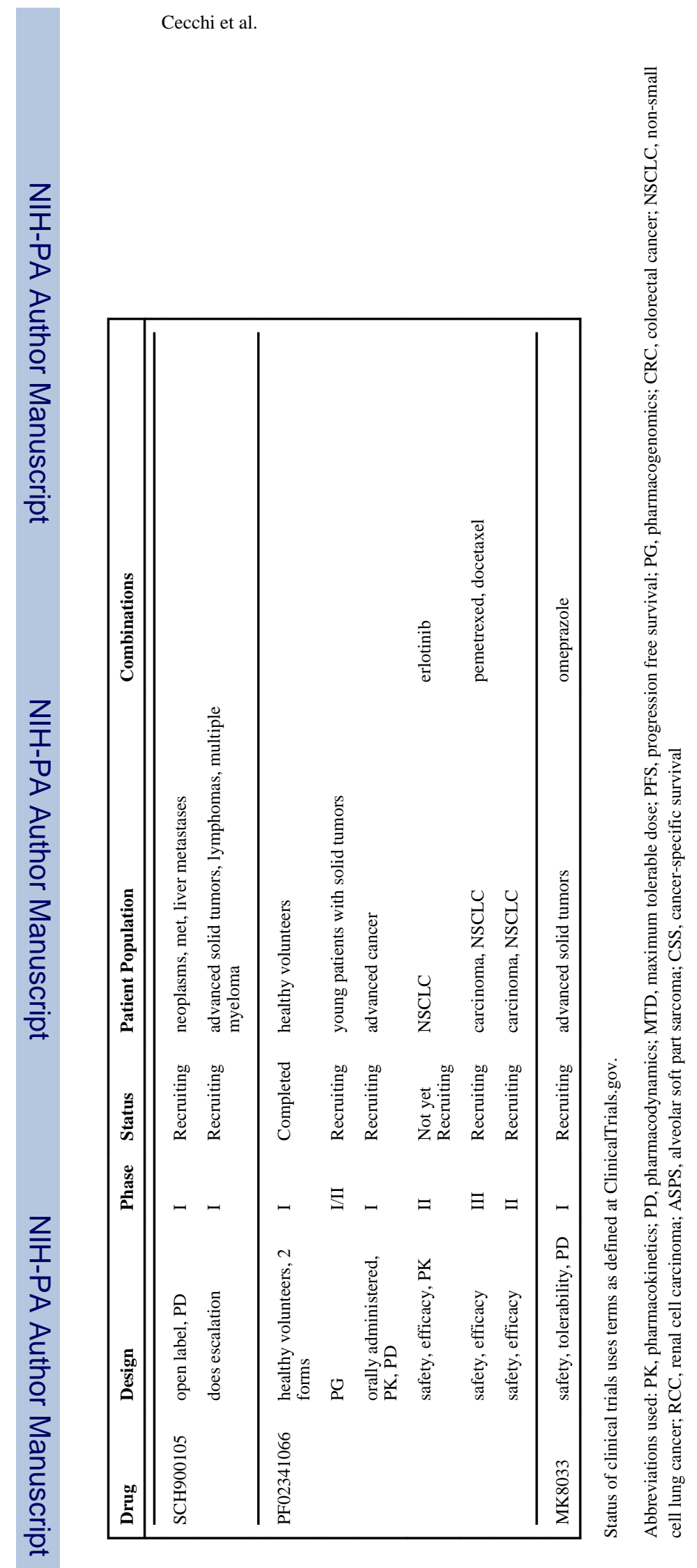

Eur J Cancer: Author manuscript; available in PMC 2012 August 06. 


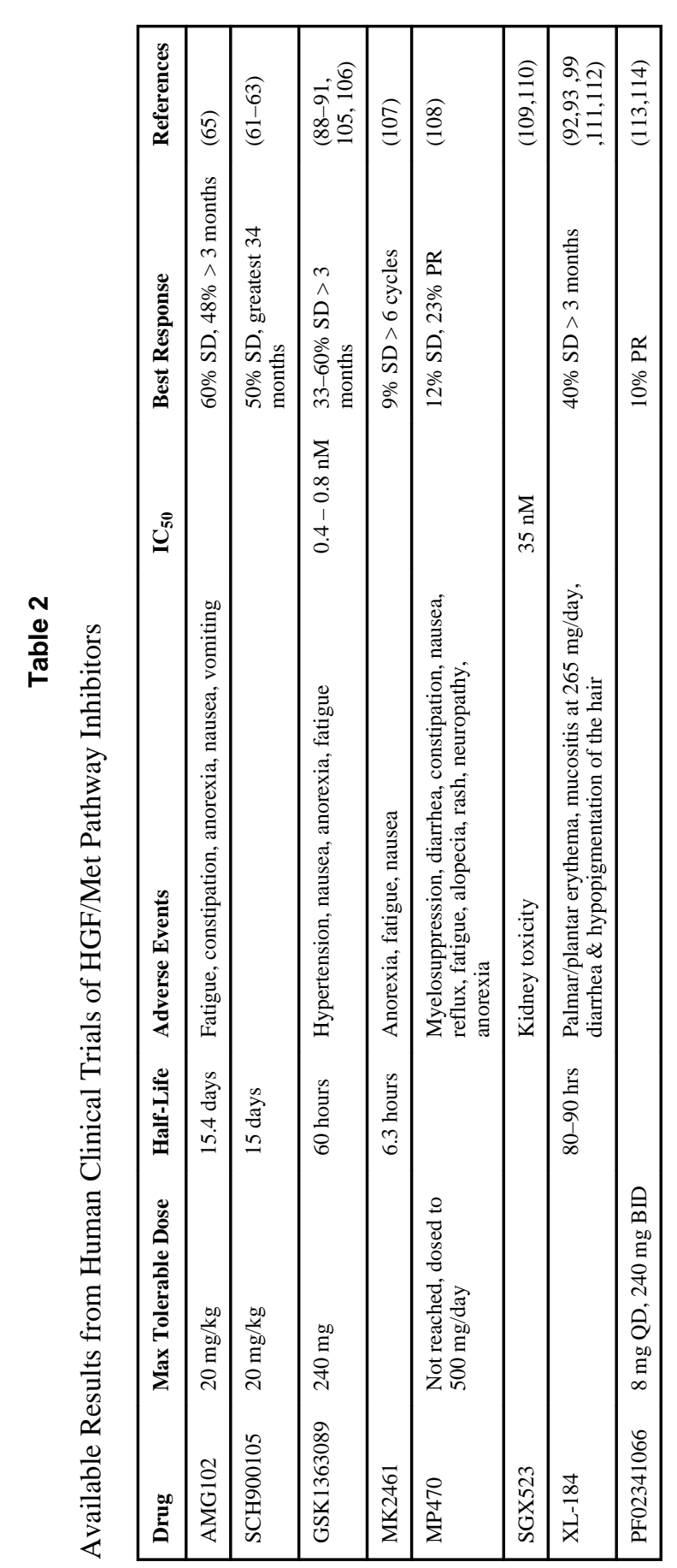

Eur J Cancer. Author manuscript; available in PMC 2012 August 06. 